\title{
Association between health literacy, general psychological factors, and adherence to medical treatment among Danes aged $50-80$ years
}

\author{
Subash Thapa ${ }^{*}$ and Jesper B Nielsen
}

\begin{abstract}
Background: Understanding behavioral factors associated with low health literacy $(\mathrm{HL})$ is relevant for health care providers to better support their patients' health and adherence to preventive treatment. In this study, we aim to study associations between low HL and socio-demographic characteristics, medication-related perceptions and experience, as well as general psychological factors among patients aged $50-80$ years.

Methods: We used a cross-sectional survey design based on a representative group of 6,871 Danish citizens aged 50-80 years returning a web-based questionnaire with socio-demographic data added from a national registry. Chisquare tests were conducted to analyze associations between low $\mathrm{HL}$ and daily use of medication and self-rated health. Chi-square tests and binary logistic regression were conducted for analyzing data from respondents using prescribed medicines daily $(N=4,091)$.

Results: Respondents with low HL were more often on daily medications (19\% [777/4,091] vs. $16 \%[436 / 2,775]$; $P<0.001)$ and were more likely to have poorer self-rated health $(P<0.001)$. Among patients on daily medications, low HL was significantly higher among men and those with lower educational attainment and lower family income. Low HL was independently and positively associated with perceptions that taking prescribed medicines daily is difficult and time-consuming, with forgetting to take prescribed medicines, and with lower satisfaction with life and poor self-assessed health.

Conclusions: Our study provides information that patients aged 50-80 years with low $\mathrm{HL}$ are challenged on their adherence to treatment plans which is not only related to traditional sociodemographic factors but also on perceptions related to taking medication per se.
\end{abstract}

Keywords: Chronic disease management, Health literacy, Medication behavior, Medication perception, Patient selfmanagement, Self-assessed health, Treatment adherence

\footnotetext{
*Correspondence: sthapa@health.sdu.dk

Research Unit of General Practice, University of Southern Denmark, J.B.

Winsløws Vej 9, 5000 Odense, Denmark
}

(c) The Author(s). 2021 Open Access This article is licensed under a Creative Commons Attribution 4.0 International License, which permits use, sharing, adaptation, distribution and reproduction in any medium or format, as long as you give appropriate credit to the original author(s) and the source, provide a link to the Creative Commons licence, and indicate if changes were made. The images or other third party material in this article are included in the article's Creative Commons licence, unless indicated otherwise in a credit line to the material. If material is not included in the article's Creative Commons licence and your intended use is not permitted by statutory regulation or exceeds the permitted use, you will need to obtain permission directly from the copyright holder. To view a copy of this licence, visit http://creativecommons.org/licenses/by/4.0/. The Creative Commons Public Domain Dedication waiver (http://creativecommons.org/publicdomain/zero/1.0/) applies to the data made available in this article, unless otherwise stated in a credit line to the data. 


\section{Background}

Health literacy (HL) entails "people's ability to access, understand, appraise, and apply health information to make decisions in everyday life concerning health care, disease prevention and health promotion to maintain or improve their quality of life" [1]. Self-management strategies, such as taking medications, for successful prevention and management of chronic diseases often require skills to look for and understand essential health information and interact with healthcare professionals [2]. Low HL levels in this regard is a common challenge shared by many patients globally [3]. In Europe, on average, 1 in 2 individuals cannot understand essential health information, while slightly lower rates of inadequate HL have been noted in the countries to the north, including Denmark, with around 1 in 5 individuals lacking the ability to understand essential health information $[3,4]$.

In the last two decades, the number of studies on predictors of HL has increased tremendously, with the majority reporting the association of low $\mathrm{HL}$ with poor socioeconomic conditions (e.g., poor educational attainment) as well as poorer health outcomes [1, 3, 5-7]. In Denmark, several studies have investigated the association of low HL mainly with poorer health outcomes, e.g. health care seeking or cancer screening behaviors, in specific patient groups [8-14]. However, only a few studies have investigated $\mathrm{HL}$ as an outcome variable, and there exists a general agreement in these studies on the association of low HL with lower education and income, unhealthy behaviors (e.g., smoking habit, alcohol consumption) and (actual as well as perceived) poorer health status $[4,12,13]$.

Patients aged 50 years and older are more likely to have chronic diseases and in need of long-term self-care and use of preventive medications [15]. Particularly, those with low HL more often have poorer health conditions and have difficulties integrating self-management practices (e.g., taking the prescribed medicines) into their daily routines $[5,16]$. This population group, however, is not often well represented in HL studies. Further, the studies that exclusively target elderly individuals often lack the comparability due to small sample size, and/or heterogeneity in measurement tools used or outcomes measured or patient groups targeted $[5,12,13,17]$. Moreover, in these studies, the association of low HL with medication-related perceptions and experience, and general psychological factors, such as willingness to take health risks and satisfaction with health and life, was not examined.

The association of poor socio-economic characteristics with low HL is plausible and well-described, while it is not clearly understood whether medication-related perceptions and experiences as well as general psychological factors would be associated with low $\mathrm{HL}$ among people aged 50 years and older. Such information may add to the existing knowledge base for health care providers to better support their patients' health and informational needs [2, 18]. Moreover, a larger and more representative sample, would allow identification of relevant patient characteristics in subgroups with low HL [18]. In this study, we aim to investigate the association of HL with socio-demographic characteristics, perceptions and experience of using daily medications as well as with general psychological factors within a representative sample of Danish citizens aged 50-80 years on daily medication.

\section{Methods}

\section{Sample and Procedure}

We used a cross-sectional survey design based on a representative sample of 15,072 Danish citizens aged 50-80 years who were randomly selected and contacted through the national digital mailbox (e-Boks.dk) in 2019. Besides the intended age selection, and the online connection required for access to their e-Boks, no other inclusion or exclusion criteria were used.

Data were collected through a web-based standardized questionnaire administered by Statistics Denmark, and socio-demographic data were added from a national registry. Two reminders were sent through the digital mail. Among the net sample, 6871 persons (45.59\%) returned a completed questionnaire and among those who returned the questionnaire, 4091 persons (59.54\%) reported to use prescribed medications on a daily basis.

\section{Measurement}

The outcome variable was "HL". Several conceptual models and measurement tools of various domains of HL have been proposed, however most of them have limited applicability due to their focus on a onedimensional concept of HL (e.g., reading ability and numeracy skill) or on one specific disease condition or one health care setting $[18,19]$. A previous Danish study from 2017 measured only 2 subscales of the full HL Questionnaire, which were "understanding health information" and "ability to actively engage with healthcare providers" [14]. In a systematic review, Chesser et al. [5] suggested that there exists no validated $\mathrm{HL}$ tool or widely agreed-upon framework to use in an older segment of the patient population in relation to selfmanagement of chronic diseases. In this view, we used a shorter version of HL scale including one item for each 4 important aspects of HL within chronic disease management, as suggested by Poureslami et al. [18]. The scale included four Likert scale questions about: (a) finding information about diseases, (b) finding professional help when ill, (c) a good understanding when communicating with physicians and (d) a good understanding on 
how to use medicines. All items were presented with 4point scales $(1=$ very easy to $4=$ very difficult). Item responses were summed up and the sum scores were dichotomized as "non-adequate" (9-16 points) and "adequate" ( $<9$ points). The cut-off was chosen to reflect the situation in Denmark, where approximately $20 \%$ of the population have previously been rated as having limited HL [4]. Cronbach's alpha for the 4-item HL scale was 0.83 .

The independent variables included sociodemographic characteristics, smoking habit and alcohol consumption, information about prescribed medicines, perceived importance of taking daily medications, perception that taking medications every day is difficult and time consuming, often forgetting to take prescribed medications, and general psychological factors, namely satisfaction with life and health, self-assessed health and willingness to take health risks. The final analysis was conducted among respondents on a daily prescription medication, excluding vitamins, minerals, omega-3 fatty acids, herbal medicines, and other equivalent products.

Socio-demographic characteristics included gender ("male", and "female"), age ("50-60", "61-70", and "7180 "), educational attainment ("basic school", "high school/ vocational education", "medium education", and "higher education"), and average family income per year("<€33, 334", “€33,334-€46,666", “>€46,667”). Smoking habits were assessed with a single item: "Do you smoke?". The variable was coded with three levels: "never a smoker", "quit smoking", and "smoker", and alcohol consumption was assessed with a single item "How many units (equivalent to one glass of wine) of alcohol do you drink usually in a week?", and answers were categorized into "nondrinker", "1-14 units" and ">14 units".
Information about prescribed medicines was measured based on three Likert-scale questions: (a) sufficient information about why to take the prescribed medicine, (b) sufficient information about how to take the prescribed medicine, and (c) sufficient information about potential side effects of the prescribed medicine. All items were presented with 6 -point scales $(1=$ strongly disagree to $6=$ strongly agree). Item responses were summed up and the sum scores were dichotomized as "poor" $(<13$ points) or "sufficient" (13-18 points). Cronbach's alpha for the 3-item scale was 0.74 .

To understand perceptions and experience of taking prescribed medications, respondents were asked to rate their agreement with "It is difficult and time consuming to take a medication daily"; and "It is important to take my medication"; and "I often forget to take my medicine". All three variables were originally answered based on a 6 -point Likert scale $(1=$ strongly disagree to 6 = strongly agree), and later dichotomized to "disagree" (1-3) and "agree" (4-6).

The general psychological variables included satisfaction with life and health, self-assessed health, and willingness to take health risks. Satisfaction with life was assessed with the single item, "How satisfied are you all in all with your life?" and satisfaction with health was assessed with a single item, "How satisfied are you with your health?" Both questions were presented with response scales from 0 (lowest level of satisfaction) to 10 (highest level of satisfaction), which were subsequently categorized into "low" (0-4), "moderate" (5-7), and "strong" (8-10). Self-assessed health was based on the single question: "How would you rate your current state of health?" which was rated on a 5-point Likert scale $(1=$ nearly perfect to $5=$ very poor $)$, and was later dichotomized into "good" (1-3) and "poor" (4-5) [20].

Table 1 Taking prescribed medications daily, self-assessed health and health literacy status of the total respondents

\begin{tabular}{|c|c|c|c|c|}
\hline & \multicolumn{2}{|c|}{ Health literacy status of the total respondents } & \multirow{3}{*}{$\begin{array}{l}\text { Total } \\
\text { n (\%) }\end{array}$} & \multirow{3}{*}{$\begin{array}{l}\text { Chi-square } \\
p \text { value }\end{array}$} \\
\hline & Non-adequate & Adequate & & \\
\hline & n (\%) & n (\%) & & \\
\hline \multicolumn{5}{|c|}{ Taking prescribed medications daily } \\
\hline Yes & 777 (18.99) & $3314(81.01)$ & $4091(59.58)$ & $<0.001$ \\
\hline No & $436(15.71)$ & $2339(84.29)$ & $2775(40.42)$ & \\
\hline Total & $1213(17.67)$ & $5653(82.33)$ & $6866(100.00)$ & \\
\hline \multicolumn{5}{|c|}{ Self-assessed health } \\
\hline Excellent & $67(8.86)$ & $689(91.14)$ & $756(11.00)$ & $<0.001$ \\
\hline Very good & $326(12.08)$ & 2372(87.92) & $2698(39.27)$ & \\
\hline Good & $487(20.66)$ & $1870(79.34)$ & $2357(34.30)$ & \\
\hline Poor & $263(29.52)$ & $628(70.48)$ & $891(12.97)$ & \\
\hline Very poor & $71(42.01)$ & $98(57.99)$ & $169(2.46)$ & \\
\hline Total & $1214(17.67)$ & $5657(82.33)$ & $6871(100.00)$ & \\
\hline
\end{tabular}


Table 2 Bivariate analysis of factors associated with health literacy among respondents on daily medications

\begin{tabular}{|c|c|c|c|c|}
\hline \multirow[t]{3}{*}{ Variables } & \multicolumn{2}{|c|}{ Health literacy status of respondents on daily medications } & \multirow{3}{*}{$\begin{array}{l}\text { Total } \\
(N=4091) \\
\mathrm{n}(\%)\end{array}$} & \multirow{3}{*}{$\begin{array}{l}\text { Chi-square } \\
p \text { value }\end{array}$} \\
\hline & Adequate $(N=3314)$ & $\begin{array}{l}\text { Non-adequate } \\
(N=777)\end{array}$ & & \\
\hline & n (\%) & n (\%) & & \\
\hline \multicolumn{5}{|l|}{ Gender } \\
\hline Male & $1543(80.11)$ & $383(19.89)$ & $1926(47.08)$ & \multirow[t]{2}{*}{0.170} \\
\hline Female & $1771(81.80)$ & $394(18.20)$ & $2165(52.92)$ & \\
\hline \multicolumn{5}{|l|}{ Age-group } \\
\hline $50-60$ & $976(80.46)$ & $237(19.54)$ & $1213(29.65)$ & \multirow[t]{3}{*}{0.302} \\
\hline $61-70$ & $1301(82.19)$ & $282(17.81)$ & $1583(38.69)$ & \\
\hline $71-80$ & $1037(80.08)$ & $258(19.92)$ & $1295(31.65)$ & \\
\hline \multicolumn{5}{|c|}{ Highest completed education } \\
\hline Basic school & $645(72.47)$ & $245(27.53)$ & $890(21.76)$ & \multirow[t]{4}{*}{$<0.001$} \\
\hline High school \& vocational & $1648(79.88)$ & $415(20.12)$ & $2063(50.43)$ & \\
\hline Medium education & $727(88.55)$ & $94(11.45)$ & $821(20.07)$ & \\
\hline Higher education & $294(92.74)$ & $23(7.26)$ & $317(7.75)$ & \\
\hline \multicolumn{5}{|c|}{ Average family income per year $(€)$} \\
\hline$<33,334$ & $1398(76.60)$ & $427(23.40)$ & $1825(44.61)$ & \multirow[t]{3}{*}{$<0.001$} \\
\hline $33,334-46,666$ & $995(82.71)$ & $208(17.29)$ & $1203(29.41)$ & \\
\hline$>46,666$ & $921(86.64)$ & $142(13.36)$ & $1063(25.98)$ & \\
\hline \multicolumn{5}{|l|}{ Smoking } \\
\hline Never a smoker & $1869(82.08)$ & $408(17.92)$ & $2277(58.54)$ & \multirow[t]{3}{*}{0.131} \\
\hline Quit smoking & $942(79.97)$ & $236(20.03)$ & $1178(28.79)$ & \\
\hline Smoker & $503(79.09)$ & $133(20.91)$ & $636(15.55)$ & \\
\hline \multicolumn{5}{|c|}{ Alcohol consumption (unit per week) } \\
\hline Non-drinker & $827(76.36)$ & $256(23.64)$ & $1083(26.48)$ & \multirow[t]{3}{*}{$<0.001$} \\
\hline $1-14$ units & $2056(82.14)$ & $447(17.86)$ & $2503(61.20)$ & \\
\hline$>14$ units & $430(85.32)$ & $74(14.68)$ & $504(12.32)$ & \\
\hline \multicolumn{5}{|c|}{ Information about the prescribed medicines } \\
\hline Poor & $189(56.59)$ & $145(43.41)$ & $334(8.23)$ & \multirow[t]{2}{*}{$<0.001$} \\
\hline Sufficient & 3099(83.19) & $626(16.81)$ & $3725(91.77)$ & \\
\hline \multicolumn{5}{|c|}{ Perception that taking medicines daily is difficult and time consuming } \\
\hline Disagree & $2669(83.69)$ & $520(16.31)$ & $3189(78.18)$ & \multirow[t]{2}{*}{$<0.001$} \\
\hline Agree & $636(71.46)$ & $254(28.54)$ & $890(21.82)$ & \\
\hline \multicolumn{5}{|c|}{ Perceived importance of taking medicines } \\
\hline Disagree & $228(80.57)$ & $55(19.43)$ & $283(7.08)$ & \multirow[t]{2}{*}{0.822} \\
\hline Agree & $3014(81.11)$ & $702(18.89)$ & $3716(92.92)$ & \\
\hline \multicolumn{5}{|c|}{ Often forgetting to take prescribed medicines } \\
\hline Disagree & $3013(82.73)$ & $629(17.27)$ & $3642(89.37)$ & \multirow[t]{2}{*}{$<0.001$} \\
\hline Agree & $289(66.74)$ & $144(33.26)$ & $433(10.63)$ & \\
\hline Satisfaction with life & & & & \\
\hline Low & $139(62.05)$ & $85(37.95)$ & $224(5.48)$ & $<0.001$ \\
\hline Moderate & $656(72.73)$ & $246(27.27)$ & $902(22.05)$ & \\
\hline Strong & $2518(84.95)$ & $446(15.05)$ & $2964(72.47)$ & \\
\hline Satisfaction with health & & & & \\
\hline Low & $543(69.26)$ & $241(30.74)$ & $784(19.16)$ & $<0.001$ \\
\hline
\end{tabular}


Table 2 Bivariate analysis of factors associated with health literacy among respondents on daily medications (Continued)

\begin{tabular}{|c|c|c|c|c|}
\hline \multirow[t]{3}{*}{ Variables } & \multicolumn{2}{|c|}{ Health literacy status of respondents on daily medications } & \multirow[b]{2}{*}{$\begin{array}{l}\text { Total } \\
(N=4091)\end{array}$} & \multirow[b]{2}{*}{ Chi-square } \\
\hline & Adequate $(N=3314)$ & $\begin{array}{l}\text { Non-adequate } \\
(N=777)\end{array}$ & & \\
\hline & n (\%) & n (\%) & n (\%) & $p$ value \\
\hline Moderate & $1121(79.39)$ & $291(20.61)$ & $1412(34.51)$ & \\
\hline Strong & $1650(87.07)$ & $245(12.93)$ & $1895(46.32)$ & \\
\hline \multicolumn{5}{|c|}{ Self-assessed health } \\
\hline Poor & $625(69.06)$ & $280(30.94)$ & $905(22.13)$ & $<0.001$ \\
\hline Good & $2689(84.43)$ & $496(15.57)$ & $3185(77.87)$ & \\
\hline \multicolumn{5}{|c|}{ Willingness to take health risks } \\
\hline Low & $855(78.66)$ & $232(21.34)$ & $1087(26.63)$ & $<0.001$ \\
\hline Moderate & $1625(80.85)$ & $385(19.15)$ & $2010(49.24)$ & \\
\hline Strong & 826 (83.86) & $159(16.14)$ & $985(24.13)$ & \\
\hline
\end{tabular}

Further, willingness to take health risks was assessed by the question, "How do you evaluate your willingness to take a risk related to your health situation?" Participants could answer on a scale from 0 (no risk willingness) to 10 (high risk willingness), and for the analyses, the scores were categorized as "low" (0-4), "moderate" (5-6) and "high" (7-10) [21].

\section{Statistical analyses}

Analyses were performed using Stata 16.0 (StataCorp LP, College Station, TX). Chi-square tests were conducted for the total respondents to analyze association of low HL with daily use of medication and self-rated health. Chi-square tests and binary logistic regression were conducted for the respondents on daily medications to examine the association of low HL with sociodemographic characteristics, perceptions and experience of taking medications as well as general psychological factors. A stepwise approach with a $p$-value $<0.20$ for variable inclusion was performed. Significance levels for testing individual variables were set at $p$-value $<0.05$.

\section{Results}

Among all respondents $(n=6,871)$, nearly $18 \%$ had low HL and $60 \%$ reported taking prescribed medicines daily (Table 1). Further, respondents with low HL were more often on daily medications $(P<0.001)$ and more likely to have poorer self-rated health $(P<0.001)$.

The bivariate analysis within daily users of prescribed medicine (Table 2) found that low HL was significantly more frequent among those having lower educational attainment and lower family income. Further, low HL was significantly more frequent among those who perceived that taking medication daily was difficult and timeconsuming, who reported poor information about the prescribed medicines, who often forgot to take their medications, who had lower satisfaction with life and who reported poorer self-assessed health.

The multivariable analysis (Table 3) found that low HL was significantly more frequent among men, those with lower education attainment and lower family income. Moreover, low HL was independently and positively associated with perceptions that taking prescribed medicines daily is difficult and time consuming, with often forgetting to take prescribed medicines, with lower satisfaction with life and with poor self-assessed health.

\section{Discussion}

Low HL was significantly more common among people who were on prescribed medications $(19 \%)$ than those who were not $(16 \%)$. A previous Danish study by Friis et al. also noted people with long-term conditions have more difficulties in understanding health information as well as in engaging with healthcare providers than the general population [12]. Data on prescribed medicines can be a proxy to having one or more long-term health conditions [22], which is why there is consistency in the given finding between Friis et al.'s study [12] and the present study, regardless of different age-groups targeted between the two studies.

Age was indeed not associated with low HL levels in the present study, which is in contrast to several studies suggesting a positive relationship between age and low $\mathrm{HL}$, especially in the oldest segment of the population $[2,5,23]$. The diminished HL levels with increasing age is mostly due to cognitive decline which is related to aging or having chronic conditions. However, this is less likely to be observed in the present study as people over 80 years who are more at risk of cognitive decline were not targeted in our study [23, 24].

Regardless of the setting, patient groups targeted or measurement tools used, low level of HL has repeatedly 
Table 3 Multivariable analysis of factors associated with health literacy among respondents on daily medications $(N=4091)$

\begin{tabular}{|c|c|c|c|c|}
\hline Variables & B & Wald $x^{2}$ & $P$ value & OR $(95 \% \mathrm{Cl})$ \\
\hline \multicolumn{5}{|l|}{ Gender } \\
\hline Male & & & & 1 \\
\hline Female & 0.18 & 4.49 & 0.034 & $1.20(1.01-1.43)$ \\
\hline \multicolumn{5}{|c|}{ Highest completed education } \\
\hline Basic school & & & & 1 \\
\hline High school \& vocational & 0.27 & 7.78 & 0.005 & $1.32(1.08-1.61)$ \\
\hline Medium education & 0.85 & 35.76 & $<0.001$ & $2.35(1.77-3.10)$ \\
\hline Higher education & 1.20 & 24.50 & $<0.001$ & $3.34(2.07-5.39)$ \\
\hline \multicolumn{5}{|c|}{ Average family income per year $(€)$} \\
\hline$<33,334$ & & & & 1 \\
\hline $33,334-46,666$ & 0.15 & 2.28 & 0.131 & $1.16(0.95-1.42)$ \\
\hline$>46,666$ & 0.28 & 5.80 & 0.016 & $1.32(1.05-1.66)$ \\
\hline \multicolumn{5}{|l|}{ Smoking } \\
\hline Never a smoker & & & & 1 \\
\hline Quit smoking & -0.07 & 0.54 & 0.460 & $0.93(0.76-1.12)$ \\
\hline Smoker & 0.14 & 1.29 & 0.253 & $1.15(0.90-1.46)$ \\
\hline \multicolumn{5}{|c|}{ Alcohol consumption (unit per week) } \\
\hline Non-drinker & & & & 1 \\
\hline $1-14$ units & 0.03 & 0.09 & 0.756 & $1.03(0.84-1.25)$ \\
\hline$>14$ units & 0.28 & 3.06 & 0.081 & $1.33(0.96-1.83)$ \\
\hline \multicolumn{5}{|c|}{ Information about the prescribed medicines } \\
\hline Poor & & & & 1 \\
\hline Sufficient & 1.11 & 77.44 & $<0.001$ & $3.05(2.38-3.91)$ \\
\hline \multicolumn{5}{|c|}{ Perception that taking medicines daily is difficult and time consuming } \\
\hline Disagree & & & & 1 \\
\hline Agree & -0.33 & 11.15 & 0.001 & $0.71(0.59-0.87)$ \\
\hline \multicolumn{5}{|c|}{ Often forgetting to take prescribed medicines } \\
\hline Disagree & & & & 1 \\
\hline Agree & -0.57 & 21.62 & $<0.001$ & $0.56(0.44-0.71)$ \\
\hline \multicolumn{5}{|l|}{ Satisfaction with life } \\
\hline Low & & & & 1 \\
\hline Moderate & 0.20 & 1.39 & 0.236 & $1.23(0.87-1.73)$ \\
\hline Strong & 0.57 & 9.98 & 0.002 & $1.78(1.24-2.55)$ \\
\hline \multicolumn{5}{|l|}{ Satisfaction with health } \\
\hline Low & & & & 1 \\
\hline Moderate & 0.05 & 0.12 & 0.718 & $1.05(0.80-1.38)$ \\
\hline Strong & 0.29 & 3.09 & 0.078 & $1.33(0.96-1.84)$ \\
\hline \multicolumn{5}{|l|}{ Self-assessed health } \\
\hline Poor & & & & 1 \\
\hline Good & 0.29 & 5.24 & 0.022 & $1.34(1.04-1.73)$ \\
\hline \multicolumn{5}{|c|}{ Willingness to take health risks } \\
\hline Low & & & & 1 \\
\hline Moderate & 0.001 & 0.0001 & 0.988 & $1.00(0.82-1.22)$ \\
\hline Strong & 0.17 & 2.01 & 0.156 & $1.19(0.93-1.51)$ \\
\hline
\end{tabular}


been associated with lower levels of education as well as income [5-7]. Demonstrating the same associations in our study support the construct validity of our measurement scale for HL. Low HL was significantly more frequent among those who reported having poor information about prescribed medications, those who perceived difficulties in taking medications daily, and those who often forgot to take their prescribed medications. These findings are in line with previous studies conducted among elderly individuals in other settings [5, 25].

Previous Danish studies suggest that literacy-related needs of the patients with lower education and income and limited HL are not often considered in the context of (self) management of chronic diseases [9, 10, 12]. Differences exist between countries and health care systems, but often it is the general practitioners that takes responsibility for medication adherence as well as continuity of care among patients on daily medications, and they should be aware of this group of patients with HL challenges. The present findings suggest that an assessment of general HL as well as information and perceptions about prescribed medication is an important step to consider in efforts to improve appropriate adherence among elderly patients. For instance, such information may help tailor patient education and counselling programs, which could effectively improve overall self-management behaviors among the patients with limited HL [18].

Further, our findings suggest that HL is not only associated with socio-economic characteristics or medication-related factors, but also with the way a person perceives his/her health status and life satisfaction. Our observed associations between poor self-assessed health and low HL among patients on daily medications is in consistent with previous Danish studies by Svendsen et al. [13] and Aaby et al. [14]. Further, the association between low HL and poorer life satisfaction particularly among elderly individuals has previously been described in a Slovenian study, although with a much smaller sample size $(\mathrm{N}=656)$ and a more narrowly defined study population [26]. In the present study, we were able to reproduce the Slovenian result, but with a larger sample size allowing for subgroup analyses on patients' characteristics. These subgroup analyses indicated that subjective well-being, which is due to a good level of self-assessed health as well as life satisfaction, is generally associated with higher HL skills and the willingness to practice selfmanagement, which is why health and informational needs of the patients with poorer subjective wellbeing should be understood and addressed also in a HL context.

\section{Strengths and Limitations}

Our study has notable strengths, which include recruitment of a large sample size to assess the relationship and allow for valid subgroup analyses. Moreover, our sample population has similar demographic composition to the Danish population in this age group, and our findings is representative for settings with similar sociodemographic and healthcare system characteristics as the Danish. The results however should be interpreted within its limitations including a modest response rate.

A major limitation of the present study is the use of several self- constructed questions including $\mathrm{HL}$, and because of this, one-to-one comparability with previous findings on these topics is more limited. For this reason, future HL studies focusing on patients' behaviors such as self-management and medication adherence should try to use different validated assessment tools. The consistency with previous studies on associations with income and educational attainment, however, supports the internal validity of the HL measurement tool used in the present study. Due to the cross-sectional design, conclusions about causality and temporality cannot be drawn. Eventually, the study was based on an equestionnaire filled in at home; and we cannot exclude that some patients received assistance completing the questionnaire. Likewise, we cannot exclude that those with very low HL did not participate at all. Selfreporting bias is possible as our e-survey relied on selfreported information.

\section{Conclusions}

The present findings indicate that patients with low HL are challenged regarding adherence to medicinal treatments, due to perceived difficulty in taking medications on a daily basis and forgetting to take prescribed medicines, as well as perceived lower quality of life.

\section{Abbreviations \\ HL: Health literacy}

\section{Acknowledgements}

We gratefully acknowledge all the respondents who generously spent their time and effort for filling in the questionnaire and sharing their experience and information for the purpose of this study.

Authors' contributions

Both authors (ST and JBN) participated in conceptualizing, analyzing, and writing the manuscript, and both read and approved the final manuscript.

\section{Funding}

This research did not receive any specific grant from funding agencies in the public, commercial, or not-for-profit sectors.

Availability of data and materials

The datasets used and/or analyzed during the current study are available from the corresponding author on reasonable request. 


\section{Declarations}

\section{Ethics approval and consent to participate}

The present study is a questionnaire study not involving human biological material. According to Danish Act on Research Ethics Review of Health Research Projects ( $\$ 14$ stk 2, June 2011), the project was not a biomedical research project and the need for informed consent was waived. Data include information that could potentially identify individuals, and the project is therefore registered at the University's Research and Innovation Office, and data handling is in accordance with the General Data Protection Regulation (EU 2016/679).

\section{Consent for publication}

The need for informed consent was waived by the ethics committee.

\section{Competing interests}

The authors declare that they have no competing interests.

Received: 14 April 2021 Accepted: 10 June 2021

Published online: 26 June 2021

\section{References}

1. Sørensen K, Van den Broucke S, Fullam J, Doyle G, Pelikan J, Slonska Z, Brand $\mathrm{H}$ : Health literacy and public health: A systematic review and integration of definitions and models. BMC Public Health. 2012, 12:80.

2. Heijmans M, Waverijn G, Rademakers J, van der Vaart R, Rijken M: Functional, communicative and critical health literacy of chronic disease patients and their importance for self-management. Patient Educ Couns. 2015, 98(1):41-48.

3. Baccolini V, Rosso A, Di Paolo C, Isonne C, Salerno C, Migliara G, Prencipe GP, Massimi A, Marzuillo C, De Vito C et al: What is the prevalence of low health literacy in european union member states? A systematic review and meta-analysis. J Gen Intern Med. 2021, 36(3):753-761.

4. Bo A, Friis K, Osborne RH, Maindal HT: National indicators of health literacy: Ability to understand health information and to engage actively with healthcare providers - a population-based survey among danish adults. BMC Public Health. 2014, 14:1095.

5. Chesser AK, Keene Woods N, Smothers K, Rogers N: Health literacy and older adults: A systematic review. Gerontol Geriatr Med. 2016, 2 2333721416630492-2333721416630492.

6. Abdullah A, Liew SM, Salim H, Ng CJ, Chinna K: Prevalence of limited health literacy among patients with type 2 diabetes mellitus: A systematic review. PLoS One. 2019, 14(5):e0216402.

7. Zhang NJ, Terry A, McHorney CA: Impact of health literacy on medication adherence: A systematic review and meta-analysis. Ann Pharmacother. 2014, 48(6):741-751

8. Gabel P, Larsen MB, Edwards A, Kirkegaard P, Andersen B: Knowledge, attitudes, and worries among different health literacy groups before receiving first invitation to colorectal cancer screening: Cross-sectional study. Prev Med Rep. 2019, 14:100876.

9. Friis $\mathrm{K}$, Pedersen MH, Aaby A, Lasgaard M, Maindal HT: Impact of low health literacy on healthcare utilization in individuals with cardiovascular disease, chronic obstructive pulmonary disease, diabetes and mental disorders. A danish population-based 4-year follow-up study. Eur J Public Health. 2020, 30(5):866-872

10. Friis K, Lasgaard M, Pedersen MH, Duncan P, Maindal HT: Health literacy, multimorbidity, and patient-perceived treatment burden in individuals with cardiovascular disease. A danish population-based study. Patient Educ Couns. 2019, 102(10):1932-1938.

11. Horshauge PM, Gabel P, Larsen MB, Kirkegaard P, Edwards A, Andersen B: The association between health literacy and colorectal cancer screening uptake in a publicly funded screening program in denmark: Cross-sectional study. Prev Med Rep. 2020, 19:101132.

12. Friis $K$, Lasgaard $M$, Osborne RH, Maindal $H T$ : Gaps in understanding health and engagement with healthcare providers across common long-term conditions: A population survey of health literacy in 29,473 danish citizens. BMJ Open 2016, 6(1):e009627.

13. Svendsen MT, Bak CK, Sørensen K, Pelikan J, Riddersholm SJ, Skals RK, Mortensen RN, Maindal HT, Bøggild H, Nielsen G et al: Associations of health literacy with socioeconomic position, health risk behavior, and health status: A large national population-based survey among danish adults. BMC Public Health. 2020, 20(1):565.

14. Aaby A, Friis K, Christensen B, Rowlands G, Maindal HT: Health literacy is associated with health behaviour and self-reported health: A large population-based study in individuals with cardiovascular disease. Eur J Prev Cardiol. 2017, 24(17):1880-1888.

15. Atella V, Piano Mortari A, Kopinska J, Belotti F, Lapi F, Cricelli C, Fontana L: Trends in age-related disease burden and healthcare utilization. Aging Cell. 2019, 18(1):e12861-e12861.

16. Dijkstra NE, Sino CGM, Schuurmans MJ, Schoonhoven L, Heerdink ER: Medication self-management: Considerations and decisions by older people living at home. Res Social Adm Pharm. 2020. https://doi.org/10.1016/j.sapha rm.2020.09.004

17. Eronen J, Paakkari L, Portegijs E, Saajanaho M, Rantanen T: Assessment of health literacy among older finns. Aging Clin Exp Res. 2019, 31(4):549-556.

18. Poureslami I, Nimmon L, Rootman I, Fitzgerald MJ: Health literacy and chronic disease management: Drawing from expert knowledge to set an agenda. Health Promot Int. 2017, 32(4):743-754

19. Haun JN, Valerio MA, McCormack LA, Sørensen K, Paasche-Orlow MK: Health literacy measurement: An inventory and descriptive summary of 51 instruments. J Health Commun. 2014, 19 Suppl 2:302-333.

20. Bruin Ad, Picavet HSJ, Nossikov A, World Health Organization. Regional Office for E: Health interview surveys: Towards international harmonization of methods and instruments / edited by a. De bruin, h. S. J. Picavet \& a. Nossikov. In.: Copenhagen: WHO Regional Office for Europe; 1996.

21. Dohmen T, Falk A, Huffman D, Sunde U, Schupp J, Wagner GG: Individual risk attitudes: Measurement, determinants, and behavioral consequences. J Eur Econ Assoc 2011, 9(3):522-550.

22. Slobbe LCJ, Füssenich K, Wong A, Boshuizen HC, Nielen MMJ, Polder JJ, Feenstra $T L$, van Oers HAM: Estimating disease prevalence from drug utilization data using the random forest algorithm. Eur J Public Health. 2019, 29(4):615-621.

23. Vogt $D$, Schaeffer $D$, Messer M, Berens E-M, Hurrelmann K: Health literacy in old age: Results of a german cross-sectional study. Health Promot Int. 2018, 33(5):739-747.

24. Murman DL: The impact of age on cognition. Semin Hear 2015, 36(3):111121.

25. Mosher HJ, Lund BC, Kripalani S, Kaboli PJ: Association of health literacy with medication knowledge, adherence, and adverse drug events among elderly veterans. J Health Commun. 2012, 17 Suppl 3:241-251.

26. Kaučič BM, Ovsenik M, Filej B: Is the holistic physical factor linked to life satisfaction in older age? Med Pr. 2019, 70(5):535-543.

\section{Publisher's Note}

Springer Nature remains neutral with regard to jurisdictional claims in published maps and institutional affiliations.
Ready to submit your research? Choose BMC and benefit from:

- fast, convenient online submission

- thorough peer review by experienced researchers in your field

- rapid publication on acceptance

- support for research data, including large and complex data types

- gold Open Access which fosters wider collaboration and increased citations

- maximum visibility for your research: over $100 \mathrm{M}$ website views per year

At BMC, research is always in progress.

Learn more biomedcentral.com/submissions 